\title{
Phlaeothripidae (Thysanoptera) diversity in Australia, with three new generic records and two new species
}

\author{
LAURENCE A. MOUND ${ }^{1} \&$ DESLEY J. TREE ${ }^{2}$ \\ ${ }^{1}$ Australian National Insect Collection CSIRO, PO Box 1700, Canberra, ACT 2601. \\ झlaurence.mound@csiro.au; ๑ https://orcid.org/0000-0002-6019-4762 \\ ${ }^{2}$ c/o Queensland Primary Industries Insect Collection (QDPC), Department of Agriculture and Fisheries, Queensland, Ecosciences \\ Precinct, GPO Box 267, Brisbane, Qld, 4001. \\ ="treefamily@bigpond.com; (1) https://orcid.org/0000-0002-7704-7750
}

\begin{abstract}
The genera Ponticulothrips, Trichinothrips and Tylothrips are newly recorded from Australia. Litotetothrips symplocosae sp.n. is described as the fourth species from Australia of this Asian genus, and Ponticulothrips mudloi sp.n. is described as the second known species in this genus that was previously known only from Japan. Trichinothrips and Tylothrips are each represented in Australia by single species, each of which is known from several countries.
\end{abstract}

Key words: Ponticulothrips, Trichinothrips, Tylothrips, faunal relationships

\section{Introduction}

The Thysanoptera fauna of Australia remains imperfectly known, with no serious surveys having been attempted over large areas in the north and west of this continent. Despite this, the number of described thrips species known from Australia has risen from about 200 in 1960 to over 1000 in 2021 (Mound \& Hastenpflug-Vesmanis 2021). The Order Thysanoptera comprises two suborders, and for the first of these, the Terebrantia, an information and identification system for the 100 genera and 340 species known from Australia is web available based on Lucid software (Mound \& Tree 2020). The second suborder, the Tubulifera, comprises a single family, the Phlaeothripidae, and is considerably larger, with up to 150 genera and about 670 species currently recognised in Australia (ABRS 2020). Illustrated identification keys are available to the species in many of these genera, but identification of genera in the Phlaeothripidae is exceptionally difficult due to the body form of many species being highly variable. This intraspecific variation is the result of sexual dimorphisms, alary dimorphisms, and remarkable polyphenic variation associated with body size. No identification system to the Phlaeothripidae genera of Australia has previously been attempted, but an illustrated identification and information system concerning all 150 genera from Australia has been completed and will be web-available early in 2022. To enable the publication of that account three genera of Phlaeothripidae are here newly recorded from Australia, together with two new species.

\section{Material and methods}

Holotypes of the two new species are in the Australian National Insect Collection, CSIRO, Canberra (ANIC). Most paratypes are in Queensland Primary Industries Insect Collection (QDPC).

\section{Phlaeothripinae taxa newly recorded from Australia}

The Phlaeothripidae fauna of Australia essentially comprises two major elements (Mound 2004). There is an 
extensive endemic fauna across the arid and semi-arid parts of the continent, with the species strictly host-specific to plants that are also Australian endemics. The other major element occurs around the northern and eastern, more humid, parts of the continent, and comprises taxa that have strong relationships to the fauna of countries to the north of Australia. Each of the new records here serves to further emphasise the faunistic relationships between northern Australia and Asia.

\section{Litotetothrips symplocosae sp.n.}

(Figs 1-3)

Female macroptera. Body and legs brown, head and tube darkest, fore tibiae brownish yellow distally, fore tarsi yellow but mid and hind tarsi brown; antennal segment II yellow on distal half, III-IV clear yellow, V yellow with extreme apex weakly shaded, VI yellow on basal two-thirds, VII-VIII brown (Fig. 3); fore wings brown around basal setae, then pale but with weak shading extending to apical third paler but margins not shaded; major setae on head and body very weakly shaded. Head as long as wide (Fig. 1), slightly constricted just behind eyes, genae narrowed to basal neck without setae; vertex with weak transverse reticulate sculpture; compound eyes with one posterolateral facet slightly enlarged; stylets retracted almost to postocular setae and about one third of head width apart; postocular setae blunt at apex, slightly shorter than dorsal eye length. Antennal segment III with 1 sense cone, IV with 3 sense cones; VII constricted to basal neck (Fig. 3). Pronotum with weak sculpture lines only at anterior and posterior, smooth medially; five pairs of well-developed setae, major setae blunt to weakly capitate; notopleural sutures incomplete. Mesonotal lateral setae small and blunt at apex; metanotal median setae very small and acute; metanotum weakly reticulate medially. Prosternal ferna large, widely separated; mesopresternum reduced to three weak sclerites; metathoracic sternopleural sutures not developed. Fore wing sub-basal setae blunt to weakly capitate; about 14 duplicated cilia present. Fore tarsus with no tooth. Pelta broadly triangular, without campaniform sensilla (Fig. 2); tergite lateral setae blunt to weakly capitate; tergite IX setae S1 and S2 long and pointed; anal setae shorter than tube.

Measurements (holotype female in microns). Body length 2600. Head, length 225; width behind eyes 235; po setae 85. Pronotum, length 175; width 325; major setae - am 45, aa 50, ml 65, epim 100, pa 95. Fore wing, length 950; sub-basal setae 50, 55, 70. Mesonotal lateral setae 35; metanotal median setae 15. Tergite IX setae 260, 250 , 200. Tube length 250. Antennal segments III-VIII length 70, 65, 65, 70, 55, 45.

Male macroptera. Similar to female in colour and structure; tergite IX setae S2 short and stout on left side but on right side long and slender with S3 short and stout; sternite VIII without pore plate.

Specimens studied. Holotype female, Queensland, Eubangee [=Eubenagee] Swamp, 5km South of Cairns, from young rolled leaves of Symplocos cochinchinensis [Symplocaceae], 17.viii.2006, (DJ Tree), in ANIC.

Paratypes: 7 females, 1 male taken with holotype (in ANIC \& QDPC).

Comments. The problems of distinguishing Litotetothrips from Thlibothrips were discussed recently (Mound $\&$ Tree 2021). These are two of the smaller Phlaeothripinae genera that were erected, but never distinguished, by Priesner for some Asian leaf-feeding species. This new species emphasises these problems, as it has character states intermediate between the two genera as currently interpreted. However, as stated in the previous publication, it is not possible to synonymise these two genera without further study of the original specimens of the two type species. The head of this new species is as long as wide, a condition considered diagnostic for Litotetothrips (in contrast to 1.1 times as long as wide in Thlibothrips), and the maxillary stylets are retracted almost, but not quite, to the level of the postocular setae. The new species is very similar to L. tareei that remains known only from two males taken on the central coast of New South Wales. From that species, L. symplocosae differs in having antennal segment VII clearly constricted to a basal neck, antennal segments III-V clear yellow with only the apex of V weakly shaded and segment VI clear yellow in the basal two-thirds; pronotal notopleural sutures incomplete, mesopresternum divided into three very small sclerites, and the pelta without campaniform sensilla. The chaetotaxy of tergite IX in the species of Litotetothrips seems to be unstable occasionally, with setal pair S2 asymmetric and reduced in length in some individuals. 


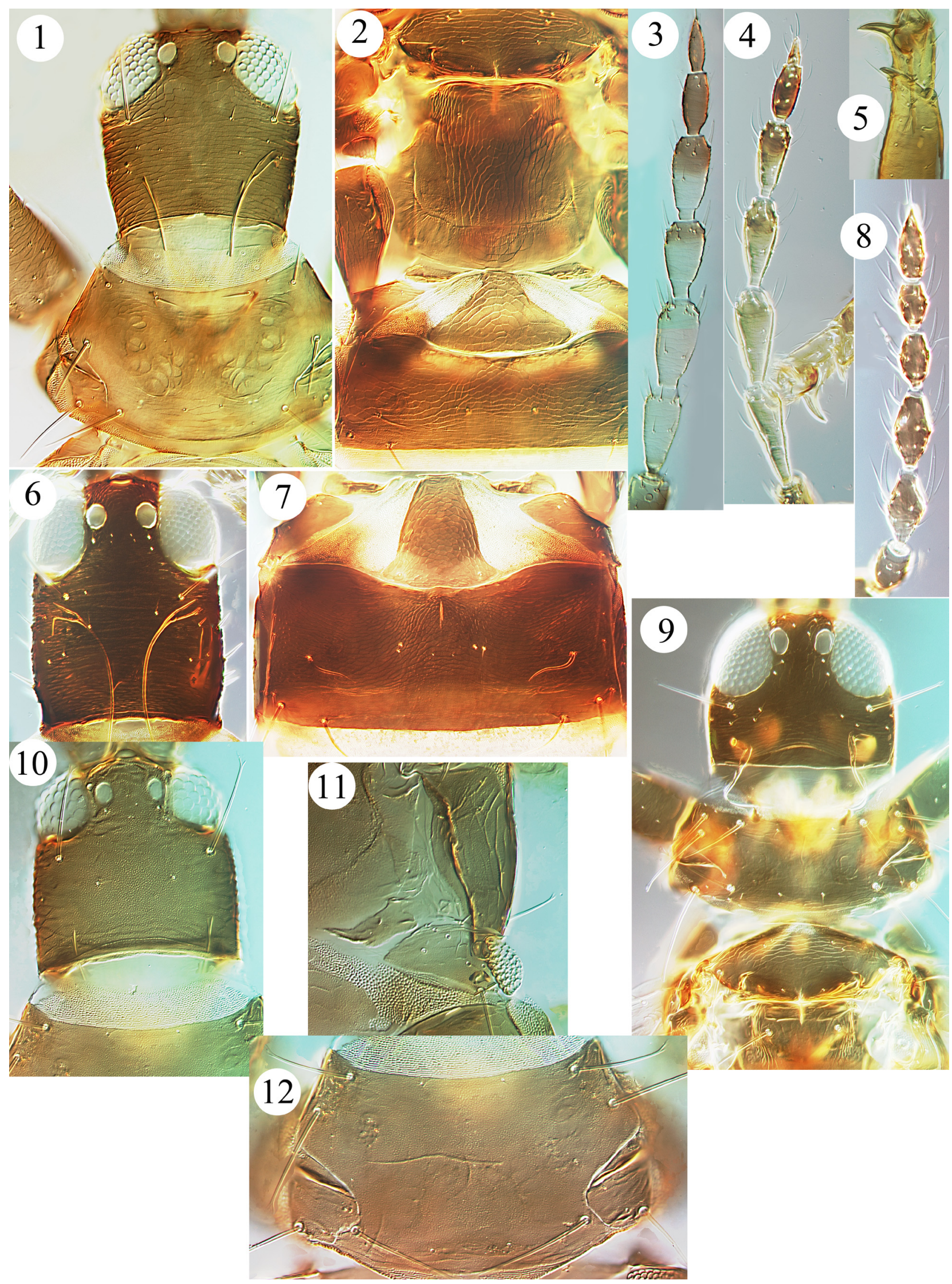

FIGURES 1-12. Australian Phlaeothripinae. Litotetothrips symplocosae sp.n. 1-3: (1) Head \& pronotum; (2) Metanotum \& pelta; (3) Antennal segments II-VIII. Ponticulothrips mudloi sp.n. 4-7 (male): (4) Antennal segments II-VIII; (5) Fore tarsus; (6) Head; (7) Pelta. Trichinothrips breviceps 8-9: (8) Antenna; (9) Head \& thorax. Tylothrips osborni 10-12: (10) Head; (11) Metathoracic ventro-lateral seta; (12) Pronotum. 


\section{Ponticulothrips mudloi sp.n.}

(Figs 4-7)

Male macroptera. Body and legs brown, fore tibiae paler distally, all tarsi yellowish; antennal segment II yellow distally, III yellow with apex faintly shaded, IV light brown in apical third, V-VI brown in apical half, VII-VIII and I-II brown (Fig. 4); fore wings weakly shaded with margins slightly darker but clavus and area around sub-basal setae brown; major setae weakly shaded. Head longer than wide (Fig. 6), genae narrowed to basal neck with several stout setae; vertex with faint transverse sculpture lines; postocular setae long and acute; maxillary stylets retracted to postocular setae and close together medially; maxillary bridge present. Antennal segment III with one sense cone, IV with 3, V and VI each with 2 sense cones; segment VIII small and broad at base. Pronotum with irregular, transverse reticulation but smooth medially; five pairs of well-developed setae, major setae bluntly pointed to weakly capitate; notopleural sutures complete. Mesonotal lateral setae small and blunt; metanotal median setae small and acute; metanotum weakly and variably reticulate. Prosternal basantra absent; ferna large and close together medially; mesopresternum transverse and fully developed; metathoracic sternopleural sutures well developed. Fore tarsus with long pointed tooth at least half as long as tarsal width; fore tibia inner apex with slightly curved and pointed tubercle (Fig. 5). Fore wing sub-basal setae rather short; 24-26 duplicated cilia present. Pelta bell-shaped (Fig. 7), with paired campaniform sensilla, slightly recessed into anterior margin of tergite II; tergites II-VI each with two pairs of sigmoid wing-retaining setae, VII with these setae straight or weak; tergite IX setae S1 long and pointed, setae S2 short and stout; tube with straight sides, anal setae shorter than tube; sternite VIII without pore plate.

Measurements (holotype male in microns). Body length 3500. Head, length 300; width behind eyes 235; po setae 100. Pronotum, length 200; width 370; major setae - am 40, aa 55, ml 55, epim 115, pa 60. Fore wing, length 1350, width 105; sub-basal setae 60, 75, 50. Mesonotal lateral setae 50; metanotal median setae 35. Tergite IX setae 210, 50. Tube length 271. Antennal segments III-VIII length 110, 95, 90, 80, 65, 35.

Female macroptera. Similar in colour and structure to the male, but with setae S2 on tergite IX about two-thirds as long as S1, and the fore tarsal tooth scarcely one-third as long as the width of the tarsus.

Specimens studied. Holotype male, Queensland, Mudlo, 200km northwest of Brisbane, barkspraying on rainforest trees, 21.xii.2011 (G. Monteith), in ANIC.

Paratypes: 2 males, 4 females, taken with holotype (in ANIC and QDPC).

Comments. The genus Ponticulothrips Haga \& Okajima is closely similar to the widespread genus Liothrips, from which it differs in having one or more pairs of stout setae laterally on the head. The genus has been known only from a single species, diospyrosi, collected in southern Japan (Haga \& Okajima 1983). Moreover, Okajima (2006) records this species from Honshu, Shikoku and Kyushu, where it is considered a pest on the leaves of persimmon trees, Diospyros kaki. The host plant of this new species remains unknown, being based on eight specimens taken from an unknown tree through the use of insecticide spraying. However, the Australian Ebony, Diospyros humilis, is widespread in eastern Queensland, where other species of this plant genus also grow. Females of the new species described here are remarkably similar to the description of dispyrosi (also images kindly supplied by Masami Masumoto). However, three of the four available males clearly differ in having a stout hook-like tubercle at the inner apex of each fore tibia; this is lacking in the fourth and smallest male that is therefore not listed above as a paratype. In both sexes, the pair of wing-retaining setae on tergite VII are usually absent, reduced or straight.

\section{Trichinothrips breviceps (Bagnall)}

(Figs 8-9)

This species was described from a single damaged male taken in Sri Lanka, that was noted to be predaceous on a psocid. Subsequently it was described under a second name from a single male taken in Malaysia although this was later synonymised (Mound 1968). Seshadri (1952) provided a clear account of its biology, indicating that the larvae fed on immature psocids and the adult thrips fed on all stages of their prey (Archipsocus ?recens Enderlein). Moreover, the prey was essential to this thrips whose larvae failed to develop in the absence of the psocids. The geographic origin of T. breviceps is not clear, because six of the eight species listed in this genus are from Brazil, Costa Rica, Panama or Florida (ThripsWiki 2021). Four of these were based on single specimens, and two of them each on two specimens. The seventh species is based on a single specimen from Java and from its description 
seems likely to be a synonym of T. breviceps. The biology is not known for any other member of the genus, but the infrequency of collection might suggest that they are all predators rather than fungus-feeders. This is a small, brown species, with the tibiae and tarsi mainly yellow, and the antennal segments brown except for the base of III. The terminal antennal segments VII-VIII are largely fused, and the sense cones on segments III and IV (Fig. 8) are longer than in any other Phlaeothripidae from Australia. The pronotal anteroangular and midlateral setal pairs are placed unusually close to each other (Fig. 9), the metascutum has no lines of sculpture with the median setae long and far apart, and the mesopresternum is remarkable in having the lateral triangles unusually large but the median area slender and largely fused to the anterior margin of the mesoeusternum. In addition to Bagnall's two type specimens, two females have been studied (in ANIC) that were collected in October, 2005 from just south of Bengalaru, India.

Specimen studied. Northern Territory, Darwin, Holmes Jungle, 1 female from rainforest barkspray, 29.v.2011 (G. Monteith), in QDPC.

\section{Tylothrips osborni (Hinds)}

(Figs 10-12)

Described originally from Massachusetts, USA, this species is widespread in eastern North America, and has been found in Panama and Trinidad. It is the only member of the genus that is considered not endemic to the Neotropics, and a few specimens have been recorded in recent years in different parts of Europe and Iran (Uzun Yiðit et al. 2021; Mirab-balou et al. 2022). As with the two specimens from Australia listed below, this thrips has presumably been introduced inadvertently to various countries by the horticultural trade. In common with other members of the genus, it is fungus-feeding in leaf litter. The members of Tylothrips are distinguished from other leaf-litter thrips by the presence of a pair of curiously long and slender capitate setae ventro-laterally on the metathorax (Fig. 11). The head, pronotum and metanotum of T. osborni lack sculpture medially (Figs 10, 12).

Specimen studied. Queensland, Brisbane, Hemmant Creek, 1 female in emergence trap, 7.xii.2010 (M.Shivas), in QDPC; Australian Capital Territory, Canberra, Mt Stromlo, 1 female beaten from Allocasuarina verticillata branch, 21.i.2022 (Alice Wells).

\section{Acknowledgements}

We are grateful for the help and encouragement of Dr Mark Schutze in providing us with access to Queensland Primary Industries Insect Collection (QDPC) and organising loans of slides to Canberra. We are also grateful to the Zootaxa editor and to two reviewers for their careful attention to an earlier draft of this paper.

\section{References}

ABRS (2020)Australian Biological Resources Study. Canberra. Available from: https://biodiversity.org.au/afd/taxa/Thysanoptera (accessed 15 February 2022)

Haga, K. \& Okajima, S. (1983) A new genus and species of Phlaeothripidae (Thysanoptera) harmful to Persimmon from Japan. Annotationes zoologicae Japan, 56, 241-245

Mirab-balou, M., Minaei, K. \& Ulitzka, M. (2022) A first record of the fungus-feeding genus, Tylothrips (Thysanoptera, Phlaeothripidae) from Iran. Journal of Insect Biodiversity and Systematics. [in press]

Mound, L.A. (1968) A review of R.S. Bagnall's Thysanoptera collections. Bulletin of the British Museum (Natural History). Entomology Supplement, 11, 1-181. https://doi.org/10.5962/p.78614

Mound, L.A. (2004) Australian Thysanoptera-biological diversity and a diversity of studies. Australian Journal of Entomology, $43,248-257$. https://doi.org/10.1111/j.1326-6756.2004.00431.x

Mound, L.A. \& Hastenpflug-Vesmanis, A. (2021) All genera of the world: Order Thysanoptera (Animalia: Arthropoda: Insecta). Megataxa, 6 (1), 2-69. https://doi.org/10.11646/megataxa.6.1.2

Mound, L.A. \& Tree, D.J. (2020) Thysanoptera Australiensis - Thrips of Australia. Lucidcentral.org, Identic Pty Ltd, Queensland. 
Available from: https://keys.lucidcentral.org/keys/v3/thrips_australia/index.html (accesed 15 February 2022)

Mound, L.A. \& Tree, D.J. (2021) Litotetothrips Priesner (Thysanoptera, Phlaeothripinae); an Asian genus newly recorded from Australia with two new species and one new combination. Zootaxa, 5027 (3), 445-450. https://doi.org/10.11646/zootaxa.5027.3.10

Okajima, S. (2006) The Suborder Tubulifera (Thysanoptera). In: The Insects of Japan. Vol. 2. The Entomological Society of Japan, Touka Shobo Co. Ltd., Fukuoka, pp. 1-720.

Seshadri, A.R. (1952) Observations on Trichinothrips breviceps (Bagnall), a little known predatory thrips from South India. The Indian Journal of Agricultural Science, 23 (1), 27-39.

ThripsWiki (2021) ThripsWiki - providing information on the World's thrips. Available from: http://thrips.info/wiki/ (accessed 1 December 2021)

Uzun Yiðit, A., Demirözer, O., Minaei, K. \& Mound, L.A. (2021) Disjunct distribution or recent introduction? The North American Tylothrips osborni in Turkey (Thysanoptera, Phlaeothripidae). Journal of Insect Biodiversity and Systematics, 7 (4), 375-381.

https://doi.org/10.52547/jibs.7.4.375 